\title{
Robert Huggins and Hiro Izushi (2011/2012). Competition, Competitive Advantage, and Clusters: The Ideas of Michael Porter (Oxford: Oxford University Press), pp. 303, p/b, ISBN 978-0-19-966042-1
}

\author{
Shiva Kumar Srinivasan \\ Behavioral Sciences, International Institute of Planning and Management, Chennai, India
}

\begin{abstract}
This review explores the arguments of the Harvard strategist Michael Eugene Porter on areas like competition, competitive advantage, and clusters that are set out in thirteen essays of this edited volume by strategy academics. It seeks to situate Porter's work by analyzing its origins, sources, goals, achievements, impact, and policy outcomes. It compares the differences between theories of comparative advantage and competitive advantage in theories of international trade, and points out that Porter's work is at the intersection of theories of competitive strategy, international trade, and theories of wealth creation. The review concludes by considering the advantages of situating firms within clusters and in comparing different types of clusters for their ability to register productivity gains. It appears that while clusters can provide firms with a competitive advantage, they do not guarantee a disproportionate increase in productivity over firms that don't seek to colocate themselves in space with other firms. There is a lot of potential in using clusters to derive a strategic advantage in approaches to regional competitiveness and development. It is however for policy makers and strategists to determine what these might be on a case-by-case basis.
\end{abstract}

Keywords: Competition, Competitive Advantage, Clusters, Regions, Strategy

\section{Introduction}

It is often thought that the work of a leading strategist is nothing more than a collection of frameworks, techniques, and tools of use only to fellow academics, experts, and business consultants. It may therefore surprise readers to find the invocation of the word 'ideas' in the sub-title of this book. This edited volume of thirteen essays is an attempt to not only evaluate the usefulness of, but also trace the origins of some of the most important ideas from business economics, economic geography, industrial organization economics, and international trade that Michael Eugene Porter, the Bishop William Lawrence University Professor of Strategy, has made his own, at the Institute for Competitiveness and Strategy at Harvard University. Those reading Michael Porter for the first time will discover that they are already familiar with his technical vocabulary though they may not know, or be able to fully appreciate, the exact resonance of his technical terms without some assistance precisely because these technical terms have passed into the socio-cultural unconscious of firms, organizations, and even nations throughout the world. It would not be a stretch to ask after reading this volume why a business economist who has revolutionized the profession of strategy and strategic management without compromising on his roots as a scholar of business economics should not be a serious contender for a Nobel Prize in economics. This is all the more so since the ideas of a number of Nobel laureates in economics like George Akerloff, Joseph Stiglitz, Michael Spence, and Robert J. Shiller have already moved into the mainstream of ideas in business schools not only in the United States, where they are based, but in management programs throughout the world. The editors of this volume are based at the Centre for Economic Geography at Cardiff University, Wales, and at Aston Business School, Birmingham, UK.

\section{Structure of the Volume}

There are three sections in this volume covering important areas and themes of Michael Porter's research such as competitive strategy, competitive advantage and the competitive advantage of nations; it also includes Porter's work on clusters and regions. There are a total of thirteen essays which not only thoroughly evaluate the topics mentioned above, but also differentiate between considering these ideas from a number of perspectives including that of academics, consultants, and practitioners. What this edited volume sets out to analyze is how Michael Porter's ideas became so successful - especially amongst practitioners - given that Porter himself is a hard-nosed academic who believes in the traditional academic virtues of methodological rigor, empirical data-based analysis, and in integrating across disciplines. Another object of analytic concern in these essays is Michael's Porter impact which is not restricted to academia, but encompasses a large number of policymakers in both the world of business and government. It would not be an exaggeration to say then that Michael Porter is the most successful business academic in the world. While nobody in this edited volume of 
essays claims to understand exactly how that came about; that is what they have to explain when they discuss the dissemination of his ideas and the diffusion of his theoretical frameworks. The difference between the work of say a philosopher who is also interested in ideas and that of Michael Porter is that Porter's impact has not only happened within his own life time, but surprisingly enough, so very early in his career. While the essayists in this book are professors of strategy, and not experts as such on the history of ideas, the enormity of Porter's impact, will require that his work is analyzed by either sociologists of knowledge or historians of social sciences in the years to come. This edited volume is a very good start to not only taking, but coming to terms with, Michael Porter's work with the deadly seriousness that we reserve for strategy academics. The first section of essays on competitive strategy and competitive advantage is an attempt to identify not only where Porter is coming from, but how he managed to make an academic discipline out of strategy. The second section is an attempt to understand whether it makes sense to invoke an analogue between firms and nations on matters pertaining to competitiveness. Is the competitiveness of nations a breakthrough analogy that will revolutionize industrial policy and business policy or is it a seriously misleading concept? Some theorists of international trade, for instance, who go along with the theoretical assumptions in models of comparative advantage stop short of going all the way with Porter's notion of competitive advantage. They believe that instead of furthering trade relations as a way of enhancing prosperity between nations, the quest for competitive advantage will detract nations and lead them up the wrong path. Are these theorists right or wrong? How do we explain the passionate response of policy makers to not only theories of competitive advantage in theories of trade, but also in areas like industrial policy where Porter's work on clusters and regional approaches to development are amongst the most successful by the sheer count of policy initiatives that have been taken in direct response to the publication of his papers and books in this area? The third section analyzes the history of cluster theory and explains how it differs from traditional approaches to industrial policy. It also analyses the different units of competitiveness and explains the differences between the sources of comparative advantage and the sources of competitive advantage within theories of trade and competitive strategy.

\section{On The Very Idea Of Competition}

The word that Michael Porter owns in the mind of the prospect - even more than strategy - is actually 'competition'. A good way of coming to terms with the cluster of ideas on competition is to notice that Porter uses the word competition more often than not as an adjective rather than as a substantive noun. Unlike German philosophers, he resists, or at least attempts to resist, the temptation of reifying the word 'Competition'. Instead, he prefers the flexibility of the term 'competitive' before the noun 'strategy'. This is a way of constantly reminding the reader that in a world bereft of competition for scarce resources, market space, customers, clients, and so forth, there is no need to make a fuss about strategy. The term 'competitive' also captures the intersubjective dimensions of strategy since firms do not strategize in private, but respond to strategic signals sent by their competitors. What Porter is very good at really is in creating a semantic field for the term competition and its derivatives. The term semantic field, as cognitive linguists explain, is an attempt to collect together a head word along with its derivatives within a spatial field to define its scope in terms of both meaning and usage. Since the meaning of a term is to be inferred from how the term is actually used in a language, exploring the scope of a term using a semantic field is an attempt to explore embryonically the scope of strategic theory insofar as it is focused on the logical or empirical derivatives of the term 'competition'. Differentiating between the 'nominal' and 'adjectival' representations of a term is also a useful way of anticipating what its theoretical applications might be in the future. What Porter brings to the area of strategy then is a sense of endless fascination with the very idea of competition. What this means is that everything we know in strategy will have to be re-thought from the point of view of competition. There are interesting analogues to this approach to doing theory in the history of the human sciences. Claude Lévi-Strauss wants to rethink everything in the history of anthropology from the point of view of 'structure'; Jacques Derrida wants to rethink everything in philosophy from the point of view of the term 'ecriture'; Jacques Lacan wants to rethink everything in theories of mind from the point of view of the 'unconscious'; and Donald Davidson wants to rethink the philosophy of language from the point of view of 'conceptual structure'. While it is by no means the case that Porter is an unabashed theorist, it is not inconceivable that we will find him more interesting from the point of view of ideas if we situate him as a theorist who brings to strategy what in a Davidsonian idiom is the "very idea of competition' as that which will animate and recreate competitive strategy for our time.

\section{Porter On Competition}

Jay Barney's opening essay, not surprisingly, is an attempt to make sense of how Porter brought together the different approaches to strategy in his time and made 'an academic discipline' out of it. The protocols of disciplinary formation is the basic stuff of what fascinates sociologists of knowledge, and Barney is right in identifying the fact that whether or not readers agree or disagree with specific aspects of Porter's work, what is really at stake for Porter is the fact that he made a discipline out of strategy. Those who think it could be 
a better discipline can only make that point insofar as Porter managed to develop the basic technical vocabulary which they can then invoke against him or bring out the inadequacies, if any, in their view, with his forays in strategic theory or competitive theory. J.C. Spender and Jeroen Kraaaijenbrink take Porter's success for granted, but attempt to explain how he got to be so successful. I think what is interesting in their attempt to do so is the fact that theorists may not be consciously aware of who they are and how they became what they find themselves to be. It is therefore important to understand the social construction of not only an academic discipline, but identify the criteria of success that is either implicit in the reception history of a theorist's work or which we can invoke in hindsight to make sense of what actually happened. Robert Hoskisson et al set out to situate the 'antecedents and precedents' that historians of strategy will need to be familiar with in order to make sense of Porter's work within the areas that are broadly described as the economic sources of strategy within theories of the firm, microeconomics, mesoeconomics, and macroeconomics. The main challenge for Michael Porter was to integrate the general approach that is characteristic of departments of business economics with the case-by-case specific approach that was characteristic of the Harvard Business School (HBS). The fact that Porter studied economics both at Harvard University and HBS made it difficult for him to be in denial about the methodological conflict that was implicit in such approaches. Porter's preoccupation with being eclectic in terms of data sources and interdisciplinary in terms of his themes and methods is a response to the cognitive dissonance that he must have experienced as a graduate student at Harvard. Nicolai J. Foss has an entire essay on this theme in the first section of this volume. I think this kind of cognitive exploration is important for any business academic even if he is not attempting to teach strategy because it shows how ideas originate from varied sources, how they are integrated across disciplines, and what the determining conditions are in making a success of these ideas from both a theoretical and practical point of view. Omar Aktouf et al also subject Porter's theories to a rigorous 'methodological and epistemological examination'. This is probably the only essay that I have read which attempts to situate Porter's work from a philosophical point of view. While Aktouf and his co-authors are not too congratulatory about Porter's forays in theory, it is important to remember that some business academics have a fondness for the structure of theory as an end in itself. Their way of taking a theorist seriously is not to make a fetish of his content, but to ask whether he will be able to pass a philosophy Tripos with honors; and if so, what role does his understanding of theory play in actually helping to secure the philosophical foundations of a given area of expertise? There are not too many other contemporary strategic thinkers about whom these questions have even been posed so directly.

\section{Do Nations Really Compete?}

There is a difference between asking whether nations really compete and whether it is desirable that they should compete. There seems to be an assumption in international trade theory that trading excludes competition since such forms of competition can lead to a nation outperforming some other nation and thereby induce a trade imbalance. These balanced approaches to international trade are not really comfortable with the idea of competition or with the idea that nations should attempt to get fit by becoming more and more competitive. The policy response to the idea of competition in trade has been quite positive. The competitiveness index that is brought out by the World Economic Forum and other bodies has been a staple feature of the emerging literature on these themes. So while the response of the policymakers has been quite buoyant, there are a number of economists who believe that a nation is not an analogue of a firm and that studying the levels of fitness or performance of a nation could be seriously misleading because it leads to a breakdown of the levels of co-operation required for nations to leverage on each other's comparative advantage. What these economists are fond of pointing out is that theories of comparative advantage are okay, but theories of competitive advantage are not. The resistance to theories of competitive advantage stems from the irrational fear that nations will wind up competing on all fronts, or that indiscriminate forms of competition (where nations seek to go beyond the confines of their comparative advantage through innovation) will lead to trade sanctions, barriers, retaliation, imbalance of payments, and so on. Or, to put it simply, comparative advantage appears to be a win-win strategy, but competitive advantage comes across for better or worse as a zero-sum game since success through innovation as opposed to exploiting factors of production has unintended consequences that, in their view, can be deeply destabilizing. The essays by Robert M. Grant, Jan Fagerberg, and Brian Snowdon in the second section of this volume explore some of these themes. Fagerberg argues that the best way to resolve this debate is to explore the empirical evidence on this theme and proceeds to do so. Fagerberg differentiates between domestic and international forms of competitiveness in the context of technology-led forms of innovation, and points out that while most studies on these topics have been mainly descriptive (meaning that the causal factors have not been clearly identified), the main advantage of using a competitive approach is that it is less likely to require protectionism in trade policy, and more likely to encourage interaction between domestic and international forms of competitiveness.

Snowdon understands Porter's interest in this area as related to not just trade theory but to the forms of theoretical inquiry that is associated with Adam Smith's Wealth of Nations. Smith is mainly interested in 
identifying the causal determinants of wealth creation in an economy. Porter's work marks the intersection between theories of trade and theories of wealth creation. To what extent can we say that trade or success in trade can itself be a determinant of wealth creation in the economy as opposed to the export of raw materials in the factor markets or even finished goods in which a nation has a comparative advantage? Porter is interested in the difference between a model of comparative advantage and a model of competitive advantage as sources or determining factors for a sustainable model of wealth creation in a nation. It is almost as if Porter is asking why Smith does not have a theory of competitive advantage in his Wealth of Nations? What is missing in most theories of wealth creation is the insight that innovation or value-chains based on innovation is the most important source of long-term wealth creation. Most theories of wealth are based on exploiting land, labor, and capital, but not on a model of technology-led innovation. Porter is anxious to get across the idea that we must notrestrict our attempts at wealth creation to the traditional factors of wealth creation, but understand that technology-led forms of innovation will be the main source of wealth creation in the years to come. To understand Porter's work on the competitive advantage of nations, we must ask ourselves how we must supplement the work of Adam Smith with a supplementary theory of technology led innovation and identify the value chains that are the most appropriate for it. Economists who resist theories of competitive advantage as a source of wealth creation presuppose that both the domestic pie and the international pie cannot be expanded; they are merely displacing their traditional preoccupation with distribution onto the space of international trade under the aegis of trade imbalances. What I think we can learn from Porter is that a trade imbalance is not a physicalist notion since innovation does not take away anything from the competitor, but creates anew something that did not exist before an act of innovation. All that trade does is to find a market space for these forms of innovation elsewhere than in the domestic markets to which producers are accustomed to producing for. So, in that sense, the Porterian analogue between the competitiveness of firms and nations is worth exploring. What theories of competitive advantage do then is to rethink traditional assumptions from the point of view of innovative value chains. They are not attempts to appropriate pre-existing forms of value but attempts to create new forms of value anddetermine the value-chains appropriate to do so.

\section{Clusters For Creating Competitiveness}

Porter began to think about clusters after he was appointed in 1985 to serve in 'Ronald Reagan's Commission on Industrial Competitiveness' to find out whether America remained competitive; and if not, what, if anything, must be done to reverse the situation. Porter headed a research task force which discovered that many successful firms were 'co-located' in space. There are a number of advantages to such forms of colocation that Porter began to describe as 'clusters'. It is not that clusters did not exist before Porter came along; it is rather that we did not appreciate their importance or have an adequate theory to explain what made them successful. The term 'cluster' however is subordinate to the term 'competition', which serves as the 'organizing principle' of Porter's work. Clusters are not specific to the American economy, but can be found throughout the world. There have however been a huge number of cluster initiatives by policymakers as a part of their industrial policy after Porter went public and began to publish his ideas in this area. A number of empirical studies have also been done in recent years to determine what the advantages and disadvantages of clusters might be, and whether economic outcomes justify the hype about clusters in the business media and in policymaking circles. It is also important to understand how clusters relate to a nation's approach to trade policy and globalization and how these phenomena interact within the over-all model of the competitiveness of nations and regions. Porter himself does not spell out the policy implications of his cluster theory but leaves it to policy makers to respond in their own way. Christian H.M. Ketels, a colleague of Porter at Harvard, has attempted to situate and explore the policy implications of cluster theory in the third and final section of this book, and the discussion above is based on the main points raised in the essay by Ketels. The notion of clusters includes not only geographic proximity, but also an understanding of the links between firms, and a sense of space and location. Edward J. Malecki points out that not all clusters are designed to be clusters in terms of policy intention but emerge from the bottom up on their own. The literature on clusters therefore explores the differences between top-down and bottom-up approaches to clusters, and what the differences are between traditional approaches to seeking advantages from the agglomerations of firms in a given location compared to Porterian clusters. The main limitation in Porter's approach, according to Malecki, is that he treats all nations as spatial constructs and does not differentiate between them on the basis of 'flows' and 'untraded dependencies'; this does not however seem to be an important limitation since what Porter is selling in the first instance is for policy-makers to accept the idea of clusters and respond with initiatives and not a total theory of clusters as an end in itself. Ron Martin and Peter Sunley explore the preoccupation with talk about competitiveness amongst not only strategists but also policy makers. Their main goal is to figure out from an empirical point of view whether firms situated inside a cluster are more competitive than firms that are not. What they really mean by competitive is whether such forms are more productive. The question that they want to answer is whether the structure of clusters will lead to productivity gains for firms that buy into this idea. If the empirical evidence is 
supportive of such an outcome, it will gain much more traction with policymakers and CEOs. They argue that most of the empirical evidence compares the performance of different types of clusters, but there is not much evidence to compare the performance of firms that are in clusters with those that are not. They conclude that there are important advantages to clustering in terms of reducing costs, expertise sharing, recruitment of employees, and in the identification of customers for firms that are knowledge intensive; but, by itself, clustering does not come with a guarantee of productivity gains. Or, to put it simply, competitive advantages (including clusters) increase the probability of success in terms of productivity, but they are not necessary and sufficient as causal factors to warrant a large-scale reorganization of the economy along the lines of clusters. Some of these arguments are analogous to the problem of special economic zones in emerging economies. What proportion of the total policy should be taken up with such initiatives? It is also not clear how a policy maker or Porter will define a cluster and whether the knowledge spill-overs and the interactions within a cluster can be a justifiable policy end in themselves to increase the competitiveness of regions or whether the policy touchstone should be hard productivity gains that can be measured in terms of 'before' and 'after' policy scenarios. They conclude by saying that clusters can be an important contribution to enhancing regional models of competitiveness, but are not reducible to or in any way synonymous with competitiveness; and furthermore, they do not guarantee a disproportionate increase in productivity gains over firms that do not seek to co-locate with their competitors in a cluster. There is however a lot of potential in the idea of clusters and it is for policy makers and strategists to determine what these might mean on a case-by-case basis.

\section{Conclusion}

The editors conclude the volume by expressing their opinions on all the contributions to this volume, but also note that while Porter's work has found enormous favor with policy makers, Porter himself does not take either his professional success or the usefulness of competitive strategy for granted. Porter in a sense is haunted by the feeling that despite several decades of strategic theory in business academia and its applications by an array of consultants, there is still a lot of confusion about what strategy is, what it can achieve, and what most firms define correctly or incorrectly as strategy. The question that still animates the strategy profession is that strategy is everywhere and nowhere. It is everywhere in the sense that everybody had heard about it and probably know of its importance, but that is not to say that every firm has a strategy going forward. Porter's recent interventions in health-care is itself an attempt to understand how sectors that are not known to think strategically think about strategy in the hope that it will give him insights on how strategy can become not only more useful but something that firms will want to think seriously about. As Porter puts it, in an interview with the editors, 'I have taken another large detour into the area of health-care delivery, but it is deeply informed by everything that came before. Also, I am learning things about strategy and competition from the health care work that I did not know. So hopefully we will have another chapter in the strategy work'. 